\title{
La piel humana en la narrativa corta tradicional
}

El papel que desempeña la piel humana en los rituales primitivos, observados a través de los tiempos, se ajusta sin lugar a dudas a una imaginada comparación de la superficie fértil de la tierra con la epidermis del ser humano. El regreso anual de la vegetación se verá remedado en un nuevo crecimiento de la piel antes perdida, una percepción fortalecida después de siglos de escudriñar la renovación epidérmica de los reptiles, los insectos y las arañas.

También parece haber sido a menudo una conjetura de hombres primitivos la creencia de que los habitantes primigenios de la tierra fuesen de piel oscura, o sea del color del mismo elemento de donde hubiesen emergido. A esta creencia responde quizá el que en tierras de Siberia, las pieles de los difuntos se cuelguen de los árboles, como para devolverlas a la naturaleza después de la muerte de sus dueños '. Por el contrario, en Mesoamérica existe una tradición, que suele contarse mientras se muele el maíz, según la cual hay una resurrección de los fragmentos de la piel del que muere, fragmentos que luego llegan a constituir el cuerpo entero de un nuevo ser, como si se tratara de una criatura recién nacida ${ }^{2}$. Junto a esta expresión de cierta equivalencia imaginada entre la vestidura de la tierra y la epidermis, pueden entresacarse de la narrativa popular cuatro consideraciones concretas:

1. La piel considerada como concreción del alma y relacionada por tanto con creencias en la inmortalidad; aquí tienen su cabida los cuentos que relatan los destinos de una piel separable.

2. La piel como expresión del temperamento, donde las diferencias cualitativas se registran según la salud o el matiz del cutis. Hay que

\footnotetext{
1 Hedwig von BeIT, Symbolik des Märchens (Berna: Francke, 1960), II, p. 41.

2 E. C. PARSONS, «The Zuñi Mo'lawia», Journal of American Folklore, 29 (1916), p. 394 , n." 1 .
} 
sumar aquí los cuentos que tratan del intercambio entre pieles humanas $\mathrm{y}$ de animales.

3. La piel excepcional, invulnerable, que en su origen, como objeto de creencia, representaba las ansias de cazadores y guerreros, plasmando acaso una tradición sobre la invulnerabilidad hipotética de los hombres primigenios, y proyectada quizá en leyendas de héroes capaces de pasar ilesos por la vida gracias a la piel, o la región de la piel que no puede ser herida.

4. La piel objeto del poder jurídico, incluyendo aquí la desollación total o parcial como castigo, quizá resultado de una intuición primitiva de relación entre las categorías 1,2 y 3 . Entran aquí, paradójicamente, las facecias moralizantes, por poco ajustada que parezca su temática atroz al ámbito del chiste ${ }^{3}$.

1. Es impresionante el lugar que ocupa la piel humana en las creencias acerca de la inmortalidad en la vida de ultratumba. Parece comprobado que se origina en una pérdida prehistórica pero simultánea, tanto de la inmortalidad como de la facilidad para cambiarse la piel ${ }^{4}$. Así es como se llega a teorizar que la criatura, en el primer dudoso momento de la existencia, sentirá, al tocarle con una mano o rozarle el mismo aire, una escocedura como si se desollara ${ }^{5}$. En el extremo opuesto de la vida terrenal, cuando se quema la piel de un recién muerto vuela desde sus cenizas la paloma de la continuidad bíblica ${ }^{6}$. Pero hay otra razón para desollar al difunto y quemar la piel -o colgarla tal vez durante algún tiempo en una iglesia como recuerdo o garantía del reposo en la otra vida - y hay que buscarla en el gran deseo del Demonio por apoderarse de ella. En las regiones remotas, «salvajes», del mundo son los espíritus malévolos de los muertos los que hacen las

\footnotetext{
3 Una rama novísima del psicoanálisis discurre sobre el «yo cutáneo», o sea, un envoltorio hipotético, presente desde los primeros momentos de la vida de la criatura, que sirve para proteger, contener y dar límites a la psiquis, y análogo a la piel somática. La experiencia de la criatura de lo que ocurre en la superficie del cuerpo promoverá la diferenciación progresiva entre el yo corpóreo y el yo psíquico. Sin embargo, en el plano figurado, estos dos no se diferencian, de ahí el interés de esta nueva teoría para el estudio de la narrativa tradicional y preliteraria. Véase Didier ANZIEU, Le Moi-peau (París: Dunod, 1985. Col. «Psychismes»).

4 Von BeIT, Symbolik, II, p. 50.

5 F. GEISSLER, Beispiele der alten Weisen des Johann von Capua (Berlín, 1960), p. 42 , n.' 29 .

6 Citado como evidencia de síntesis entre creencias cristianas y precristianas por Valentín MERKelBACH, Der Grabhügel (Diss. Maguncia, 1964), p. 120.
} 
veces del diablo ya universalizado en la Europa y la América convertidas al cristianismo.

En «El regateo sobre la piel en el ruedo», un guardador de tumbas tiene el deber de proteger la piel de su vecino difunto $-\mathrm{o}$ tal vez la piel y el dinero- desde dentro de un círculo en la tierra, mientras que el Demonio trata en vano de regatearle esa misma piel ${ }^{7}$. En un cuento parecido, el Demonio se ve obligado a conceder la piel de un difunto a un piadoso sobreviviente, aunque antes el muerto ya se la tenía «prometida» mediante la costumbre de exclamar, durante su vida de sarnoso: ¡Al diablo con esta piel mía! ${ }^{8}$. Otra prueba de cómo se le antoja al Demonio la piel humana se observa en cuentos en los que se disfraza con ella para efectuar algún engaño, o cuando, hasta después del exorcismo, es capaz de dejar tras de sí su señal, la piel o por lo menos una oreja encogida «como una nuez del nogal inmadura»?

En otros continentes, lejos de las tradiciones del ámbito europeo, suelen existir otros seres interesados en adquirir la piel de los mortales: entre los inu (esquimales) se cuenta de una madre demoníaca que desuella a su propia hija a raíz de los celos que siente, revistiéndose luego ella misma con la piel ${ }^{10}$. Por supuesto, son universales las tradiciones de brujería, cuyas adeptas se sirven de guantes, riendas y máscaras hechos de la piel de los muertos ${ }^{11}$.

2. Los colores de la piel expresan el temperamento y el atractivo de un individuo, además de la posible duración de su vida ${ }^{12}$. Leemos que en España las manchas del cutis de una mujer - mujer que en todos los aspectos ocultaba su carácter «manchado»- sólo eran perceptibles cuando se reflejaban en un espejo o en las aguas de un pozo encantado; el rey rehusa como prometida a esta «Dorian Grey» del cuento tradicional ${ }^{13}$. La piel negra evidencia, en cuentos europeos, el poder

7 AARne-Thompson, Types of the Folktale (Helsinki, 1964), n." 815.

8 Types, n." $813 \mathrm{C}$.

9 E. NyndGe, A Booke Declarynge the Fearfull Vexasion of one Alexander Nyndge. Beynge moste Horriblye tormented wyth an evyll Spirit... (Londres, 1615, reimpreso East Lansing, Michigan, 1940), p. 10. Se da como un acontecimiento en el condado de Suffolk en 1575 .

10 Von BeIT, Symbolik, I, p. 136.

11 Jacqueline SimPSON, Icelandic Folktales and Legends (Londres, 1972), pp. 46 y 180-181.

12 Esteve Busquets I Molas, La piel en el folklore (Vic: Colomer, 1977), cap. IX. «Cuidado y color de la piel», p. 181.

13 AARne-Thompson, Types, n. $870 \mathrm{D}$. 
maléfico. Es el caso de la bruja en alguna de las múltiples versiones de «Las tres naranjas» ${ }^{14}$. Ese color puede desaparecer, sin embargo, cuando se deshace un encantamiento, como en el cuento polaco de «La princesa negra». En otro español, la rivalidad entre dos mujeres conduce a la ruina del cutis de una de ellas; su enemiga ha sustituido el ingrediente de una preparación cosmética por un extracto de piel de tortuga. Aquí tenemos una tradición que resulta de la impresión, universalmente percibida, de lo nítidamente infrahumano de la apariencia de la piel de reptil ${ }^{15}$.

La piel de reptil y la humana a menudo son intercambiables, como aparece en los cuentos chinos de «El rey rana» y «El niño rana», donde se produce el fenómeno del cambio definitivo de piel en el momento de efectuarse el matrimonio ${ }^{16}$. Pero la piel del reptil puede traer consigo un gran peligro: si se come asada, como en «El herrero de Pont de Pile», la desafortunada llegará a parir un hijo con piel de víbora ${ }^{17}$. Mientras que en Africa una muchacha que había contravenido cierto tabú es condenada a mostrar en sí misma la textura y colores de una piel de serpiente hasta que se baña en leche, deshaciendo así el encanto ${ }^{18}$. Por otra parte, si la piel del reptil se quema, o bien puede quedar deshecho el encantamiento, como en "El rey Lindorm», o puede contribuir a la desertización de toda una comarca africana ${ }^{19}$. Idéntico intercambio se observa en varias tradiciones cuando se trata de la piel de una foca, un erizo, de un conejo o del lobo, abarcando en este último caso una gama de explicaciones del fenómeno del lobishomen (lobizón, loup-yarou, etc.) ${ }^{20}$. Después de la destrucción de la piel, en cada caso se rompe el hechizo: la revelación del prometido o del esposo, o tal

\footnotetext{
If Aarne-Thompson, Types, n." 408.

is Busquet i Molas, La piel, p. 25.

16. W. EBtRHARD, Typen Chinesischer Volksmärchen (Helsinki, 1937, «F.F.C.», 120), núms. 42 y 43. Se podría aducir también el cuento "Pondandi» (Siberia, véase Von BEIT, Symbolık. II, $\mathrm{p}$ 41), quien también el día de su boda cuelga la antigua piel de un árbol.

17 Von BEIT, Symbolik. I, pp. 120-122.

is (i. M. THEAL, Kaffir Folk Lore. A Selection (Londres, 1866, reimpreso 1970), pp. 67.71 .

19) Von BeIT, Symbolik. II, p. 201. Para el cuento africano (oriental), L. KoHL-LARSEN, Funf Madchen auf seinem Rücken (Kassel, 1969), pp. 27-29.

20 Philippe MÉNARD, «Les Histoires de loup-garou au moyen âgew, Symposium in honorem Prof. Martin de Riquer (Barcelona: Universitat, 1984), pp. 216 (el concepto de versipellis) y 218-219 (la piel de lobo). Compárese AARne-THOMPSON, Types, n." 441.
} 
vez el término de los poderes de brujos y brujas ${ }^{21}$. Por último, se conocen ejemplos en los que es imposible deshacerse de la piel de animal, por ejemplo cuando algún malévolo ha querido simular al Demonio en forma de chivo, o cuando se destruyen por casualidad los «recambios» de piel de conejo del que, para engañar, adoptaba alternativamente la forma de hombre y la de conejo ${ }^{22}$.

3. En todas las épocas ha existido la creencia de que algunos seres poseen desde el nacimiento la capacidad de mantenerse invulnerables. Prueba de ello son los memorabilia como el del soldado francés que pasaba incólume bajo los tiros de los del rey de Bohemia. Ostentaba una piel impenetrable a las balas y unos apéndices carnosos debajo de los brazos, perceptibles desde el día en que nació. Sólo una bala de vidrio fue capaz de alcanzarle letalmente ${ }^{23}$. Un concepto muy parecido y originario también de Bohemia, es la invencibilidad de las armas husitas mientras llevaran la piel talismánica de su héroe muerto, Žžžka, que había sido convertida en tambor en combates victoriosos ${ }^{24}$. Por último, el sentido de muchas ordalías reside en la crencia en la inocencia por medio de la invulnerabilidad de la piel.

4. El desollar parte del cuerpo de muertos y vivos existió en los códigos medievales como castigo, junto a otros. En los martirologios de todas las religiones aparece la mención de la desollación: como la de los santos Bartolomé y Julián, o la del heresiarca Mani y el rabino Akiba, en sus respectivas leyendas ${ }^{25}$. Se cuenta del rey godo Totila que fulminó su ira contra la persona de un obispo, sacando de la espalda del prelado la piel como en una especie de correa ${ }^{26}$. La historia de Marsias, en la mitología griega, sirve para fortalecer la idea tanto de la irracionalidad como de la disparidad del mundo de los dioses frente

21 Américo PAREDES, Folktales of Mexico (Chicago 1970), p. 27, n." 9, y (entre otros) E. S. PARSONS, "Folk-Lore of the Sea Islands, South Carolina», Memoirs of the American Folklore Society, 16 (1923), n." 63: "Fuera de su piel».

22 J. M. CARritere, Tales from the French Folk-Lore Of Missouri (Evanston, Illinois, 1937, reimpreso 1970), pp. 130-134, n. 26: «L' P'tsit Lapin».

23 Handbuch des deutschen Aberglaubens, col. 1583.

24 Handbuch, col. 1584

25 Para la leyenda del martirio de San Julián, de cuya piel se hizo fabricar el rey persa un cojín, véase Jacobus de Voragine, Legenda aurea (edición de Jena, 1925), p. 145 .

26 J. GRIMm, Deutsche Rechtsalterthümer (1889, reimpreso Darmstadt, 1965), II, p. 291. 
al de los seres humanos ${ }^{27}$. En un plano más terrenal, aparece con frecuencia el tradicional cuento de «Las tres tiritas de piel»: el que rompe con su promesa de no enojarse (o sea, de que «tendrá correa») sufrirá el castigo de sacrificar tres tiritas de piel de su espalda ${ }^{28}$.

Aparte del exemplum conocidísimo de Heródoto retratándonos la justicia del rey Cambises descargada en un juez corrupto, el cuento moralizador suele mostrar su cariz gracioso aplicándose, muchas veces, a la diferencia entre la piel del campesino y la de la gente refinada: los guantes de piel de perro sirven para suavizar las manos de una gentil dama, pero carecen de efecto las bragas de la misma materia en el trasero áspero de un plebeyo ${ }^{29}$. Un campesino asturiano con una enfermedad en la piel vuelve a aplicarse con éxito un emplasto de excremento de vaca, ya que un ungüento «civilizado» de la farmacia no ha surtido efecto ${ }^{30}$. Aquí se observa, una vez más, la equivalencia notoria ente la piel del primitivo y la superficie de la tierra misma; ambas se benefician del mismo «ungüento». Estas facecias moralizadoras abarcan las numerosas versiones de aquel escarmiento de la vanidad senil, " $L a$ vecchia scorticata», no muy diferenciado del de otro cuento misógino que nos llega de la antigüedad griega, «Las nueve pieles de las mujeres»: al ser azotada la mujer por su verdugo, emite ocho gritos distintos mientras simula otros tantos movimientos de animales, según el azote va atravesando una piel tras otra. Sólo al llegar el látigo a la novena piel emite ella una verdadera voz de mujer ${ }^{31}$.

Repasando esta selección, entresacada de las narrativas cortas tradicionales, se llega a intuir que la piel humana es plurivalente. Más misteriosa y difusa en sus manifestaciones en la cuentística que la lengua, el corazón, las manos, la barba, o hasta la cabeza misma, es la parte del cuerpo que mejor expresa el eslabón entre el universo animal y el de los espíritus, entre la vida corpórea y los atisbos de un más allá.

\section{Alan SOONS \\ State University of New York at Bufalo}

27 Moralizado por Apolodoro. Véase J. G. Frazer (recopilador), Apollodorus, The Library (Londres, 1921, reimpreso 1961), I, p. 30, n." 1.

28 AARne-Thompson, Types, n." 1000. En recopilaciones más recientes (Córcega), Geneviève MASsignon, Contes corses (Aix, 1963), n." 23; y (Croacia) M. BoskoviC-Stulli, Kroatische Volksmärchen (Munich y Viena, 1975), pp. 218-225, n." 49.

29 Joe Miller's Jests, or the Wits Vade mecum (Londres, 1739, reimpreso 1963), p. 34, n." 115.

30 María Josefa CanelladA, Cuentos populares asturianos (Salinas: Ayalga, 1980, «Col. popular asturiana», 48), pp. 120-121, «Dermatología».

31 AARNe-Thompson, Types, n." 877. 
Como atributo del ser humano, la piel es polivalente; da origen a creencias acerca de la inmortalidad, del temperamento del sujeto y de la invulnerabilidad del guerrero. Son estas creencias a su vez fuente de relatos tradicionales. La percepción de la vegetación y de la piel de los reptiles cada año renovadas es sugestiva para el narrador primitivo: el macrocosmos también tendrá su piel. De todo esto resulta un amplio abanico de cuentos y leyendas, ya faceciosos, ya ilustrativos de potencias demoníacas.

As an attribute of the human being, the skin is polyvalent; it forms the basis for beliefs about immortality, about individual temperament, and about the invulnerability of legendary warriors. These beliefs lie in their turn at the origin of many traditional folktales. The perception of the renewal each year of the earth's vegetation, and of the skins of reptiles, is suggestive for the primitive narrator: the macrocosm also has a covering of skin. So one may identify a wide spectrum of related stories and legends, sometimes facetious, sometimes illustrative of the powers of the Devil. 